\title{
Research on the Construction of Fashion Design Curriculum Group Under the Background of Emerging Engineering Education
}

\author{
Yizhou Zhang \\ School of Culture Communication \& Design, Zhejiang University of Finance \& Economics, Hangzhou, China \\ Email address: \\ 188496172@qq.com \\ To cite this article: \\ Yizhou Zhang. Research on the Construction of Fashion Design Curriculum Group Under the Background of Emerging Engineering Education. \\ International Journal of Education, Culture and Society. Vol. 6, No. 1, 2021, pp. 15-20. doi: 10.11648/j.ijecs.20210601.13
}

Received: February 14, 2021; Accepted: February 27, 2021; Published: March 4, 2021

\begin{abstract}
In order to adapt to the new requirements of the new economy for engineering talents, the new engineering came into being and put forward a series of new requirements for the traditional engineering higher education. Firstly, the author clarifies the new requirements of the new engineering. That is, master the basic theoretical knowledge of modern design, proficiently use design methods and skills, and possess the ability of aesthetics and planning. And put forward higher requirements in terms of the application of disciplines, the intersection and comprehensiveness of traditional disciplines and new technologies, innovation awareness and innovation capabilities, and practical capabilities. Reflects on the curriculum setting problems of the fashion design specialty, For example, the training objectives are backward, the courses are loosely structured and there is duplication of content, and there is a gap in the connection between theory and practice courses, and many more proposes the objectives, methods and contents of the construction of fashion design curriculum group under the background of emerging engineering education, Finally, the research results will be fed back to teaching and tries to propose some possibilities for the education reform of the fashion design specialty under the new economic environment.
\end{abstract}

Keywords: Emerging Engineering Education, Fashion Design, Curriculum Group

\section{Introduction}

Since the 13th Five-Year Plan for National Economic and Social Development of the People's Republic of China was put forward [1] (hereinafter referred to as the $13^{\text {th }}$ Five-Year Plan), in order to adapt to the new requirements of the new fast developing economy for engineering talents, the higher education department of Ministry of Education issued the notice about how to start a new engineering research and practice [2], and the concept of new engineering education quickly aroused widespread attention of higher education. Faced with a series of new requirements such as "new concept", "new structure", "new mode", "new quality" and "new system", the textile industry is facing great challenges. How to develop a group of new engineering talents with solid theoretical knowledge, strong practical ability, excellent innovation consciousness and ability and construct a reasonable and effective curriculum group, has become an important problem that higher educators in textile industry need to think about.

\section{Current Situation and Main Problems of the Fashion Design Curriculum Group}

In this background, the following problems are common in the teaching of fashion design curriculums:

\subsection{There Is a Gap Between the Teaching of Fashion Design and the Cultivation Objectives of New Engineering Talents in Universities and Colleges}

The cultivation objective of the current fashion design specialty is to master the basic theoretical knowledge of modern design, skillfully apply design methods and skills, and have the ability of aesthetic appreciation and planning. On this basis, the new economy puts forward higher requirements of subject application in fashion design, intersecting and 
comprehensibility between the traditional subject and new technology, and innovation consciousness, innovation ability and the practical ability of the talents for the talent cultivation.

\subsection{The Contradiction Between the Subject Nature and the Actual Cultivation Tendency in the Fashion Design Specialty}

Fashion design specialty is a subject under the textile science technology and clothing technology (according to national standard GBT 13745-2009). Meanwhile, it is a specialty that closely combines artistic aesthetics with engineering technology. However, the fashion design specialty in most colleges and universities is set up in the art institute recently, which is dominated by curriculums composed of art, and supplemented by some basic textile technology curriculums.[3] The "one-leg" training mode of "attaching importance to art and ignoring industry, and pushing the whole with art" can still survive in the current economic environment, but it no longer meets what the new economy wants of interdisciplinary practical and innovative talents in the future.

\subsection{The Construction Among the Curriculums Is Scattered and Lacks of Logical System Integration}

At present, the curriculum construction of the fashion design specialty is mainly based on the concrete construction of a single curriculum. The teaching content is relatively independent and there is only a simple relationship among the curriculums [4] (as shown in Figure 1, taking the fashion design specialty in our school as an example). Teachers focus most of their energy on the content structure and teaching methods of the single curriculum they are responsible for, and pay little attention to the position of the curriculum in the whole fashion design curriculum system and the relationship with other curriculums, which may make students feel confused in the specific and long-term learning process.
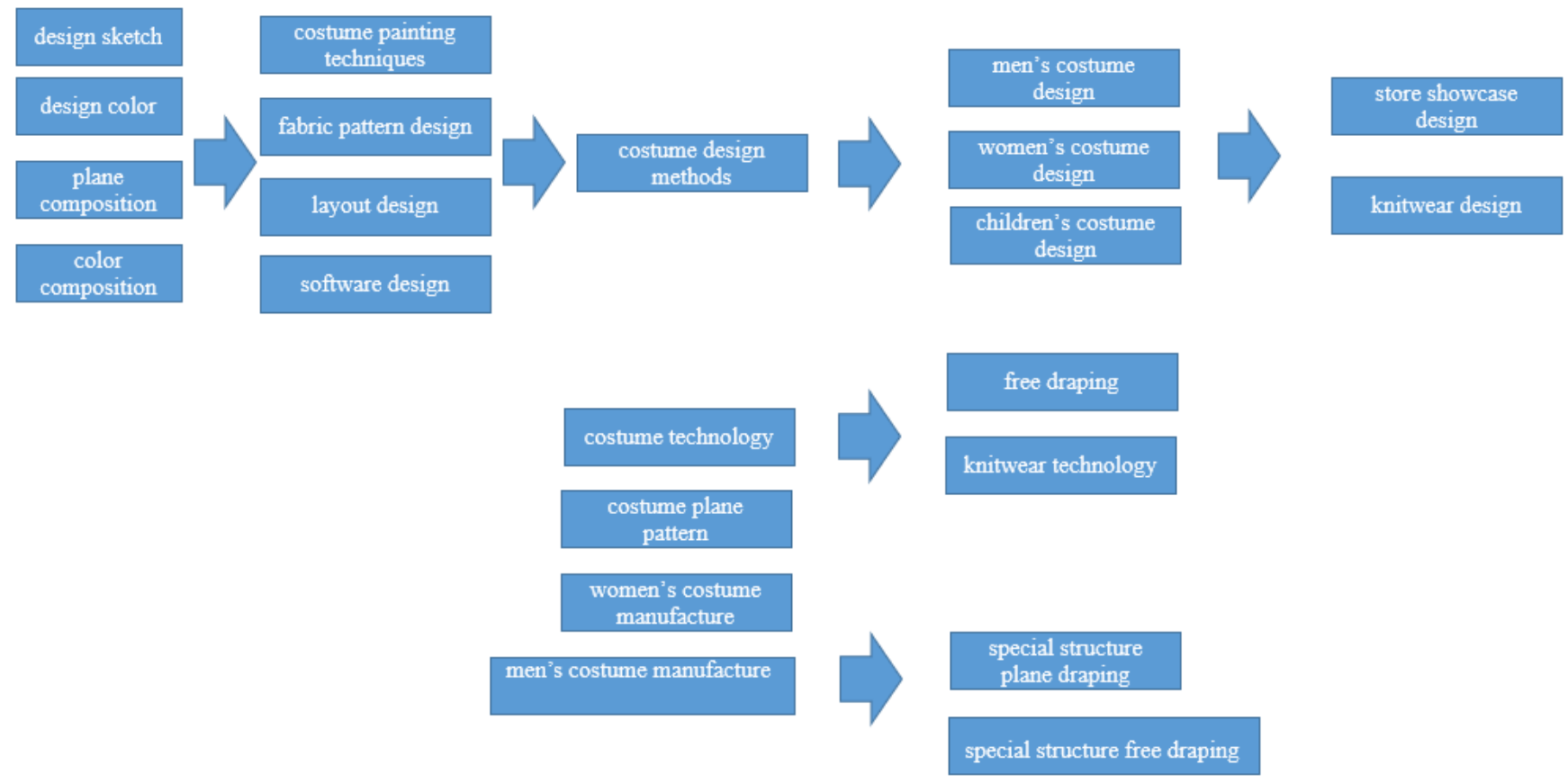

Figure 1. Current connection relationship among the curriculums setting of fashion design specialty.
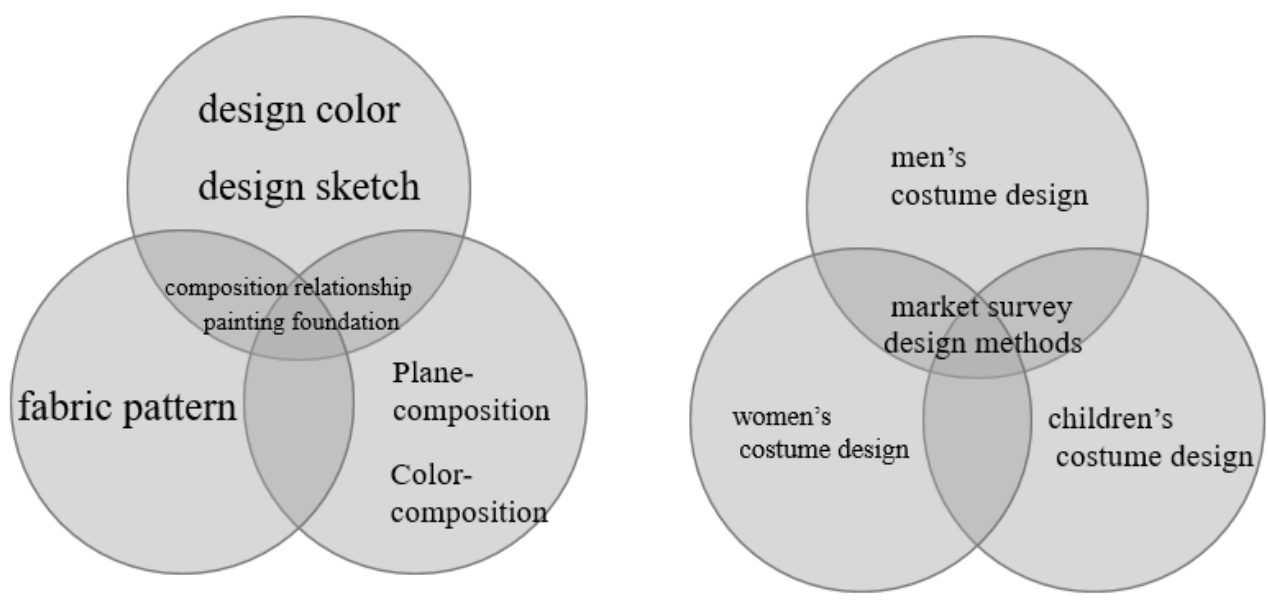

Figure 2. Current existing repetition among the curriculums setting of fashion design specialty. 


\subsection{There Are Low-Level Repetition Among Some Curriculums, and the Curriculum features Are Vague}

In the current curriculum structure of fashion design, there are more or less low-level repetition of curriculum content in both basic curriculums and specialized curriculums, such as design color curriculum and color composition curriculum in basic courses. There is a certain degree of repetition in curriculum objectives, content and methods (as shown in Figure 2). In this way, the features and emphases between curriculums are not distinct enough, which makes students feel bored in the learning process and the learning content is not rich enough [5].

\subsection{There Are Barriers in the Connection Between Theoretical Curriculums and Practical Curriculums}

Fashion design is a major that has higher requirements for aesthetic consciousness and modeling ability, which requires a close combination between design curriculum and practical production curriculum in the process of cultivating students. [6] However, in the actual operation, it is found that due to the difference in professional direction between design and manufacturing teachers (art and engineering), the teaching content, methods and results are deviated in the course connection process.

\subsection{New Teaching Methods Still Need a Lot of Practice and Targeted Adjustment}

In practice teaching, it abandons the traditional teaching method that takes teacher as center to unilaterally cram, and constantly tries to bring new teaching modes such as flipped classroom, project-driven, OBE (results-oriented) into the classroom. [7] The rational use of these new teaching modes will be conducive to the improvement of teaching quality and the cultivation of students' abilities. However, at the same time, some new teaching methods begin to be abused, and the teaching method that attaches importance to methods and ignores objectives has a negative effect on the teaching quality conversely [8].

\section{The Objective and Significance of Curriculum Group Construction}

\subsection{Objective of Curriculum Group Construction}

In view of the requirements of the new economy for new engineering talents, the curriculum system is adjusted, that is, using the curriculum group construction of fashion design enables the curriculum objectives curriculum content, curriculum setting, teaching concept, teaching methods and teacher team construction of the fashion design specialty can be comprehensively and systematically improved, [9] and effectively solve many problems such as outdated training objectives, too independent curriculum setting, repeated curriculum content, and the connection between theoretical curriculums and practical curriculums to improve the teaching quality, and cultivate more fashion design talents with solid theoretical knowledge, strong practical ability, excellent innovation consciousness and innovation ability for the society.

\subsection{Significance of Curriculum Group Construction}

First, through the research and practice of this project, a series of more advanced theoretical explorations on the teaching objectives, teaching contents and teaching methods of fashion design under the background of new engineering education are obtained and a new way of fashion design professional education is found, which makes the fashion design professional education of traditional industry can better adapt to the requirements of the new economy. Second, under the new engineering education background, the establishment of a new teaching framework of fashion design specialty, has a certain applicability and promotion.[10] In the end, guiding the practical teaching with study theory, improving teaching quality, optimizing the teaching resources, and enriching teaching content, all contribute to form the fashion design professional teachers team with advanced teaching concept, and cultivate a series of talents with solid basis of theory, practice experience and creative ability and consciousness of fashion design to meet the demand of the new economy.

\section{Content of Curriculum Group Construction of Fashion Design under the New Engineering Education}

\subsection{Clarify the Requirements of New Engineering for Fashion Design Talents, Optimize Cultivation Objectives, and Improve Teaching Concepts}

The key to optimizing cultivation objectives is to study the gap between the "new requirements" and the "current requirements" of the new engineering. The fashion design specialty is a very applicable specialty. It serves the traditional manufacturing industry. However, Under the development trend of new economy and new industry, it puts forward the new requirements of possessing more solid material science foundation, more advanced engineering technology comprehensive ability, learning ability and innovation ability for the fashion design talents driven by fashion concept. In this context, it is necessary for educators to timely change their teaching concept, rather than simply positioning teaching to meet the market demand. Although in the short term, it is conducive to students' employment. While in the long term, it will lead to a lack of sustainable development of students. What the new economy needs is to more cultivate students' problem awareness, problem solving ability and lifelong learning ability, interdisciplinary ability, innovation awareness and innovation ability, so that students are still in an advantageous state in the re-employment. In view of this trend, it is necessary to promote the cultivation objectives to guide 
the direction of the subsequent teaching reform. [11]

\subsection{Adjust the Curriculum Setting to Solve the Contradiction Between the Subject Nature and the Actual Cultivation Tendency}

First, nowadays, a large number of most curriculum setting of fashion design specialty in Chinese colleges and universities is given priority to main art construction curriculum and basic engineering curriculum, which causes a lot of students have grandiose aims but puny abilities. Fashion design professional curriculum can tilt to art construction curriculum a little, but you can never imbalances.[12] second, engineering technology curriculum is mostly composed of the basic costume manufacture craft, such as the manufacturing method of a kind of costume, the use of the sewing machine, the making of manual plate and lacks of frontier technology curriculums of costume engineering, such as advanced machine (such as shape data scanning, laser cutting machine, etc.), advanced software (such as Virtual Fashion, My Label 3D Fashion by Bernina, etc.) and other related curriculums. Balancing the volume of art design curriculum and engineering technology curriculum and improving the frontier engineering technology curriculum are the core content of ensuring the objective of cultivating new engineering fashion design talents.

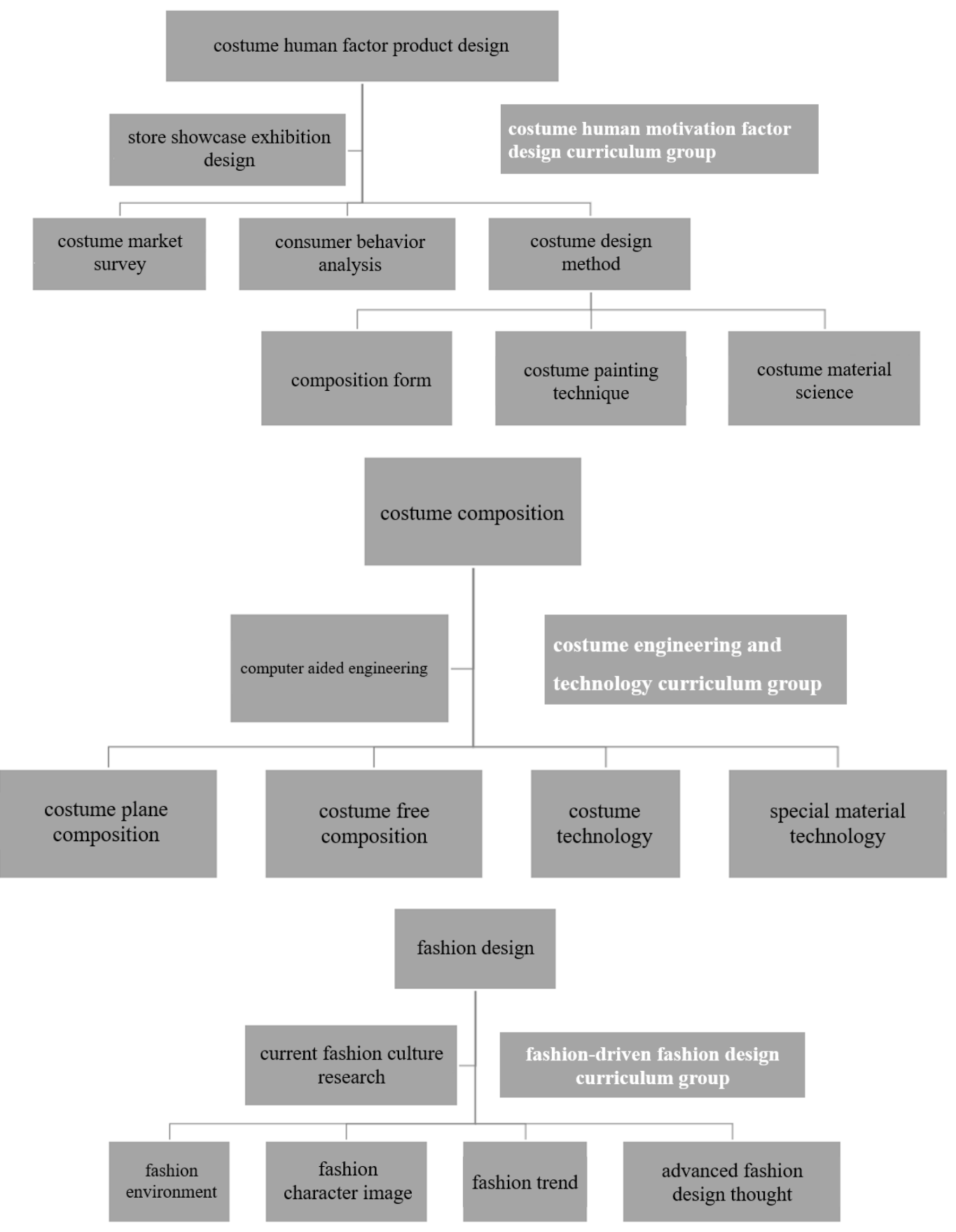

Figure 3. Curriculum group framework of fashion design specialty. 


\subsection{Establish the Framework of the Curriculum Group of Fashion Design Specialty According to the Cultivation Objectives}

Curriculum group of fashion design is a curriculum group based on professional design curriculums, which is composed of mutually independent and interrelated curriculums. The construction of curriculum group should distinguish the primary and secondary, take measures according to local conditions, rely on the characteristics of running a school and the objective of talent cultivation, and take the core curriculums as a breakthrough to establish construction of curriculum group. Fashion design specialty in colleges and universities generally offer core curriculums of plastic arts, engineering technology and comprehensive design, but most of these curriculums are relatively independent and lack of connection, leading to students' partial subjects.[13] The author intends to construct the curriculum group from three aspects of engineering technology, humanistic motivation and fashion design. Based on this, the core curriculum group can be divided into costume engineering and technology curriculum group, costume human factor design curriculum group and fashion-driven fashion design curriculum group (see Figure 3) to make full use of the advantages of the school and the specialty, meet the needs of the new environment, construct a distinctive fashion design curriculum group and put forward the possibility for cultivating a higher level of new engineering fashion design talents.

\subsection{Optimize the Curriculum Content and Deal with the Mutual Curriculum Relationship Within the Curriculum Group}

The curriculum group is built on the basis of integrating the curriculum, optimizing the content and improving the teaching quality. So, in the actual work process, it is necessary to pay attention to the problem solution on curriculum itself and the relationship between the curriculums. [14] In terms of curriculum content, appropriate deletion should be made to the curriculum content that does not meet the requirements of the cultivation objectives and the teaching content also should be timely updated. In terms of the relationship between curriculums, the logical relationship between curriculums should be clarified, the boundaries between curriculums should be made clear, and the objectives of curriculums should be clarified, so as to form a curriculum structure with distinct levels and clear relations.

\subsection{Integrate Teaching Resources and Build a Teaching Team}

The new requirements brought by the new engineering will certainly bring higher requirements to the teaching resources of fashion design specialty, so it is necessary to expand the scope of teaching resources, enrich the reserve of teaching resources, and improve the quality of teaching resources, including Integrating self-compiled textbooks, establishing high-quality case databases and multimedia databases corresponding to curriculum groups, expanding the practice base of university-enterprise cooperation and updating lab facilities, teaching AIDS, software and so on according to new curriculum cultivation requirements. Teachers are not only the designers of curriculum group content integration and optimization, but also the implementers of curriculum group teaching. Therefore, as the main body of curriculum group construction, first of all, the teaching concept and objective of the teacher team should be unified, so that everyone's teaching direction is the same. Secondly, the allocation of teaching staff should be enriched, such as inviting experienced professionals in the industry to serve as practitioners and bring first-hand information of the market to students. Thirdly, teachers must not only master the content of a certain curriculum they are familiar with, but also master the content and positioning of other curriculums related to the curriculum group. If necessary, professional groups are required to prepare lessons together and maintain effective communication with each other to prevent unclear objectives and gray areas between curriculums. Finally, according to the new requirements of the new economic environment, teachers should constantly improve their professional ability, try to dabble in other related subjects, often go out and keep in touch with the society and the market to constantly improve their innovation vitality and ability.

\subsection{Reform the Teaching Methods According to the Actual Needs of the Curriculum Group}

Teaching methods emerge in an endless stream. According to the needs of different curriculum groups, the appropriate teaching methods should be chosen. Purposeful teaching methods reform is an important way to achieve this teaching reform. For example, in the fashion-driven design curriculum group, the teaching method of flipped classroom can be tried to use, which requires students to study before class, ask questions and discuss in class, make more effective use of class time, and solve practical problems that books and the Internet cannot solve. In the costume human factor design and development curriculum group, project driven teaching methods can be tried to apply to provide students with virtual or actual projects and enable them start learn around solving practical project. Meanwhile, taking project completion status as a standard of achievements inspection, it can enable students actively explore, thinking and complete the study requirements.

\subsection{Establish Scientific Management and Evaluation Mechanism to Ensure the Smooth Progress of Teaching Reform}

Clear evaluation standard and scientific management are the important guarantee of curriculum group construction. Only through scientific and effective management and evaluation mechanism can curriculum group construction be effectively supervised and promoted. It should be carefully organized, planned and carried out step by step to make it conform to the professional reality and be feasible. [15] At the same time, a working group should be established to clarify 
the person in charge of the curriculum group and ensure the smooth construction of the curriculum group.

\section{Conclusion}

The new economy and new scientific and technological revolution are taking place. In order to support the service innovation-driven development and a series of national strategies such as "Made in China 2025", the Ministry of Education is actively promoting the construction of new engineering education. In this general trend, as an important part of the traditional manufacturing industry, fashion design is actively carrying out teaching reform, which is the only way to adapt to the trend development. Therefore, on the basis of clarifying the cultivation objectives of fashion design specialty under the background of new engineering education, a reasonable curriculum group structure should be constructed, curriculum settings should be optimize, the relationship between curriculums within the curriculum group should be clarified, curriculum content and teaching methods should be improved and the allocation of the curriculum group should be enriched, so that the fashion design curriculum group can effectively serve for the cultivation of new engineering fashion design talents.

\section{References}

[1] Outline of the 13th Five-Year Plan for National Economic and Social Development of the People's Republic of China [N]. People's Daily, 2016-03-18 (001).

[2] The Guide of New Engineering Education Construction (Beijing Guide) [J]. Research on Higher Engineering Education, 2017 (04): 20-21.

[3] Xia Yanjing. Discussion on the Curriculum Structure of Art Design Undergraduate Specialty in Chinese Universities [D]. Nanjing University of the Arts, 2007.

[4] Wang Min, Pan Xianwei. On the Reform of Curriculum System of Fashion Design Specialty in Higher Vocational Colleges [J]. China Vocational and Technical Education, 2003 (10): 51-52.

[5] Chen Zhihua, Zhu Jianjun. Construction of Practical Teaching System of Costume Specialty in Higher Vocational Education [J]. Vocational and Technical Education, 2007, 28 (08): 44-46+94-95.
[6] Liang Jun. Research on Teaching Mode of Fashion Design Studio [J]. Journal of Northeast Electric Power Institute, 2005 (03): 42-45.

[7] Xue Sunan. Discussion on Flipped Classroom Education Mode of College Fashion Design Curriculum Based on the Environment of "MOOC + SPOC" [J]. Art Science and Technology, 2016, 29 (05): 351-352.

[8] Xia Liping, Guo Dun. Innovation and Exploration of Fashion Design Teaching based on Flipped Classroom [J]. Heilongjiang Textile, 2015 (03): 16-17.

[9] Qian Haiqing. Preliminary Exploration on the Teaching Reform of Fashion Design Curriculum in Applied Undergraduate Colleges [J]. Textile Report, 2017 (11): $32-33+35$

[10] Qi Lirong. Teaching Reform and Content Setting of Fashion Design Curriculum [J]. Journal of Nanning Vocational and Technical Institute, 2005 (03): 6-9.

[11] Wu Yonghong. Discussion on the Construction of Curriculum Group System for Fashion Design Specialty [J]. Vocational Education Forum, 2011 (32): 50-51+54.

[12] Wu Zhiming, He Yijun, Liu Dongyun, Yao Yi, Zhang Qin. Brief Discussion on Group Teaching Reform of Costume Technology Curriculum [J]. Journal of Wuxi Education Institute, 2004 (04): 83-84.

[13] Gu Chunhua. Research on the Construction of Fashion Design Curriculum Group under the Background of Emerging Engineering Education [J]. Journal of Ningbo University (Education Science Edition), 2019, 41 (01): 95-98.

[14] Chen Keqian. A Comparative Research on the Art Design Curriculum in Chinese and American Universities [D]. Zhejiang Normal University, 2009.

[15] Yang Juan, Yang Youguo. Teaching Reform of Clothing Process Basis Curriculum Based on the OBE Concept [J]. Textile and Costume Education, 2020, 35 (06): 522-524.

\section{Biography}

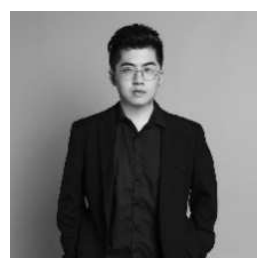

Zhang Yizhou (1989-), Male, native of Huaibei, Anhui Province, lecturer in fashion design, School of Culture Communication \& Design Zhejiang University of Finance and Economics. Research Area: Sustainable Fashion Design/Slow fashion 